\title{
Life cycle inventories to assess value chains in the South African biofuels industry
}

\author{
Alan Brent \\ Centre for Renewable and Sustainable Energy Studies, School of Public Leadership, Stellenbosch University \\ Rovani Sigamoney \\ Department of Chemical Engineering, University of Cape Town
}

Harro von Blottnitz

Department of Chemical Engineering, University of Cape Town

Sibbele Hietkamp

Energy and Processes, Material Science and Manufacturing, CSIR

\begin{abstract}
The South African government ratified a new biofuels industrial strategy at the end of 2007. The feasibility study that forms the basis of the strategy highlights the potential environmental implications of such a strategy. However, at present there is no structured approach to evaluate the environmental profile of the scenarios within the strategy. This paper introduces life cycle inventories whereby the environmental profiles of biofuel value chains may be evaluated meaningfully. The scope of the paper focuses on the seed extraction biodiesel production scenarios of the strategy. The inventory analysis shows that the inputs and outputs of the farming unit process are sensitive to the type of crop and region of produce. Water usage is a highly variable parameter, which emphasises the importance of rainfall and irrigation to the overall burden of the biodiesel system on water resources. Crop yields may differ by a factor of two, which is a significant difference in terms of land and non-renewable energy resources requirements. The oil and meal/cake content of the seed proves to be the most important parameter that influences the initial unit processes of the value chains; almost all the inputs and outputs of the farming unit processes, for all the crops, range in the order of a factor of two due to this parameter. The uncertainties associated with the logistic system in the value chain also have major implications. Further, should there be no market offset for the meal/cake co-products, the waste treatment requirements would be highly uncertain. Very little uncertainties were detected in the biodiesel production unit process, although the energy efficiency, and sustainability, of the overall production
\end{abstract}

system remains questionable. The paper identifies a number of limitations with inventory sets that need to be addressed through further research efforts to improve the environmental evaluations of a biofuel value chain in South Africa for policy-making purposes.

Keywords: biofuel, biodiesel, life cycle inventory, life cycle assessment, environmental proile

\section{Introduction}

The South African government (DME, 2007) ratified a biofuels industrial strategy in December 2007. The strategy aims to achieve a biofuels average market penetration of $2 \%$ of liquid road transport fuels, namely petrol and diesel, in the country by 2013. This biofuels target will contribute up to $50 \%$ to the 2013 national renewable energy target of $10000 \mathrm{GWh}$ (DME, 2003). It is envisaged that the target is achievable without excessive economic support by utilising surplus agricultural capacity. The target is based on local production, both agricultural and manufacturing, to provide the benefits of employment, economic growth and Black Economic Empowerment (BEE) through the value chain (see Figure 1) (NBTT, 2006).

The South African biofuels industrial strategy is primarily based on a feasibility study of the National Biofuels Task Team (NBTT, 2006), the viability of which has been critiqued (Brent et al., 2009). The feasibility study briefly describes the perceived environmental impacts associated with the biofuels 


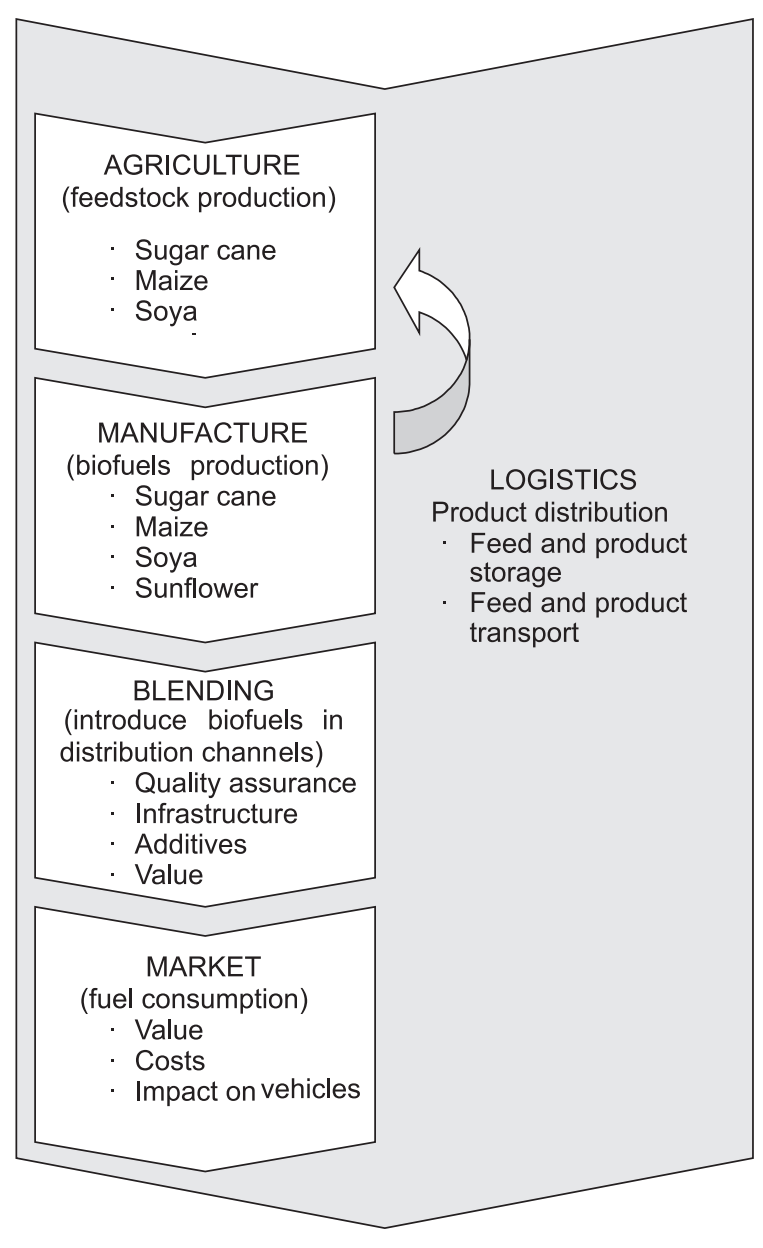

Figure 1: Diagram of the biofuels production value chain

Source: NBTT, 2006

value chain, and mainly focuses on feedstock of sugar cane and maize, for bioethanol, and soybean and sunflower, for biodiesel.

Some key conclusions from the feasibility study are as follows (NBTT, 2006):

- Increased cultivation of energy crops could have additional impacts on South African soils; conservation agriculture (Derpsch, 2005) should be adopted by all farmers as it makes more economic sense, through fewer inputs, and improves soil fertility and thereby greater yields.

- Biodiversity can be threatened through the expansion of cultivation as mono-cropping (Scholes and Biggs, 2005), use of pesticides and fertilisers, and the release of genetically modified or alien crops into nature all impact negatively; an analysis of the potential impact on biodiversity of expansion of the cultivation areas in South Africa, beyond the targeted surplus agricultural capacity, should be undertaken.

- An extended energy crop industry could further increase pressure on South Africa's limited water resources (Berndes, 2002), not only for irrigation production, but also with rain fed produc- tion of both annual and perennial crops; and biofuels processing needs to be carefully assessed for its impact on the water reserves in a given catchment.

- An introduced biofuels value chain could lead to increased pollution to natural resources; biofuels processing needs to be assessed against industrial pollution regulations to determine whether the processes are adequately covered, and health and safety regulations need to be assessed for their ability to adequately deal with the challenges of potential small-scale processing plants.

- The biofuels value chain is not carbon neutral; and a life cycle approach should be used when considering support for programmes that are chosen based on their capacity to mitigate climate change.

\section{Objectives of the paper}

Life cycle assessment studies have been conducted on bioenergy production from biomass (Jungmeier et al., 2002; Pro et al., 2005), and on bioethanol (Kim and Dale, 2006; von Blottnitz and Curran, 2007) and biodiesel (Spirinckx and Ceuterick, 1996; Kim and Dale, 2005) production in particular. However, these types of studies have not been conducted to increase the understanding of the environmental implications of the South African biofuels industrial strategy.

This paper subsequently set out to develop South African life cycle inventories of biodiesel production as a first step towards comprehensive analyses of biofuel value chains. The paper focuses on commercial-scale seed extraction biodiesel production, although it is envisaged that the inventories will be developed further for small-scale and other distributed and co-production routes. The paper also considers the environmental impact profiles of such inventories for policy-making purposes.

\section{Scope of the study}

In the short-term, the feasibility study of the National Biofuels Task Team (NBTT, 2006) focuses on conventional food crops, namely first-generation biofuels production. Three crops were subsequently chosen as likely feedstock for a commercial biodiesel value chain in South Africa (Nolte, 2007): soybean, sunflower, and canola. For these three crops, the total biodiesel value chain production costs are estimated to be below 1US\$ per litre (Nolte, 2007). The biofuels industrial strategy envisages that the crops will be produced in the Mpumalanga, KwaZulu-Natal, Eastern Cape and Western Cape Provinces (see Figure 2).

\subsection{Functional unit and reference flow}

The choice of functional unit depends on the focus of life cycle assessment studies. If the intent is to 


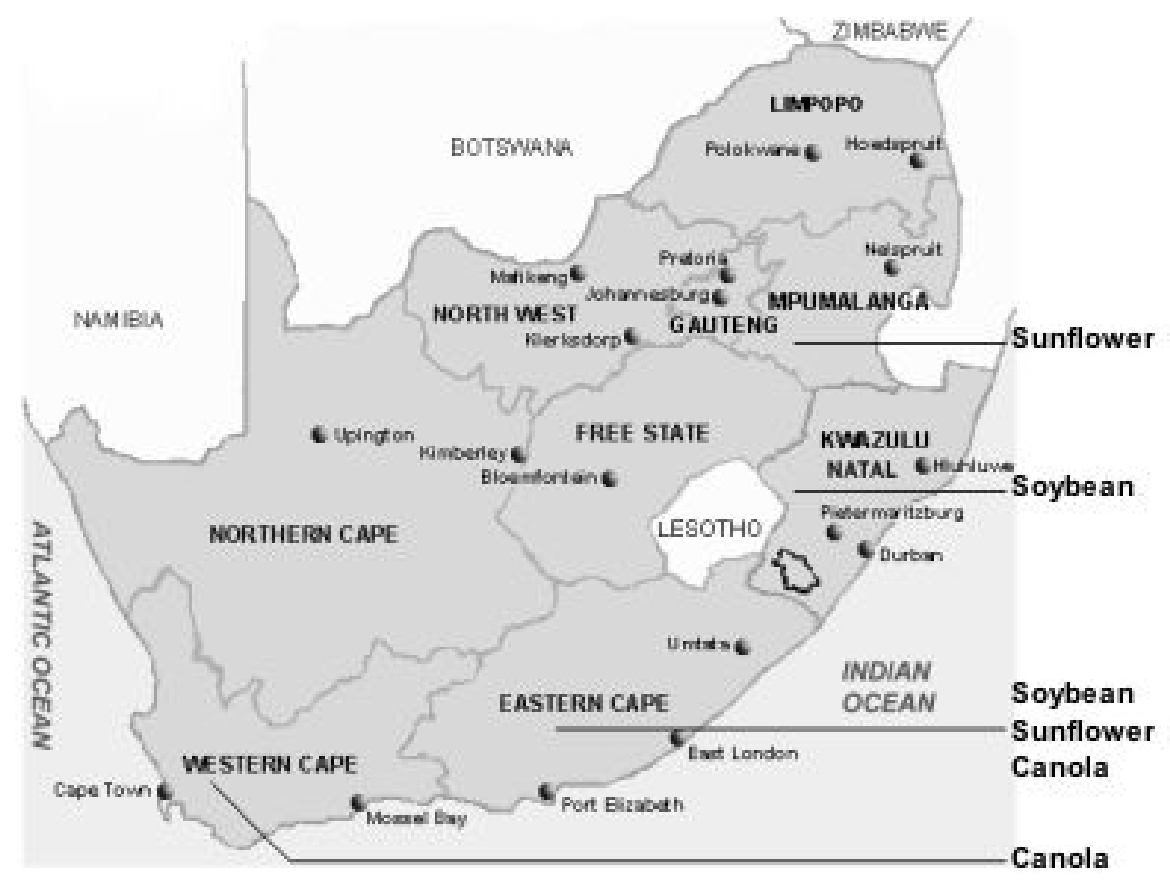

Figure 2: Envisaged biodiesel feedstock production in South Africa

examine the environmental performances of different cropping systems, then an area of land planted has been used as a functional unit (Kim and Dale, 2005). When fuels are compared, then the functions of the fuel products are normally used; for example, the work delivered by a diesel engine or a certain mass transported over a distance (Sheehan et al., 1998).

Since the aim of this paper is to establish environmental profiles of biodiesel products, a unit of product, over a one-year production period at a commercial-scale facility, was chosen as reference flow, namely 19500 tonnes of $100 \%$ biodiesel (B100) produced per annum (19.5 kt/yr). This equates to a $2500 \mathrm{~kg} / \mathrm{hr}$ production facility, which is deemed an optimum biodiesel plant size for commercial purposes in the South African context (Nolte, 2007).

\subsection{Initial system boundaries and data quality}

The unit processes that were included in the initial system boundaries and the main system flows are depicted in Figure 3. A large-scale commercial biodiesel industry has yet to be realised in South Africa (Nolte, 2007). Indeed, it is perceived that under the current dispensation, a large-scale biofuels industry is not sustainable unless the government provides more attractive incentives to encourage private sector investment (Tait, 2005). The study therefore required the postulation of a hypothetical commercial biodiesel industry, based on the current South African soybean, sunflower and canola production and crushing industries and fuel transportation infrastructure, and (First World) methyl ester transesterification technology (Harding et al., 2008). These life cycle phases of conventional seed extraction biodiesel production were considered only, namely the use phase was excluded. To this end, the environmental implications of using the blended biodiesel and conventional petroleum diesel, as per the national biofuels industrial strategy, have not, until now, been investigated in detail in the South African context, although the required blending ratio is deemed to play a minor role in changing the environmental impacts of the use phase.

Industry and national data was primarily used for the farming, oil pressing, and biodiesel production (Harding et al., 2008) unit processes, and a field trip was conducted to update some of the process parameters based on current practices and planned developments. The field trip included agricultural associations in South Africa, farmers, oil press operators, and future biofuels production developers.

The economic inputs to the three main unit processes were included in the system boundaries. However, since industry and national data availability was a constraint for these inputs, international databases and biodiesel studies (Sheehan et al., 1998) were used. The consequence is that certain economic inputs are reported directly as elementary flows, or environmental inputs; for example, crude oil and coal inputs due to diesel and gasoline usage in the farming equipment. The economic outputs, namely the meal/cake from the oil pressing unit process and the two by-products/waste streams 


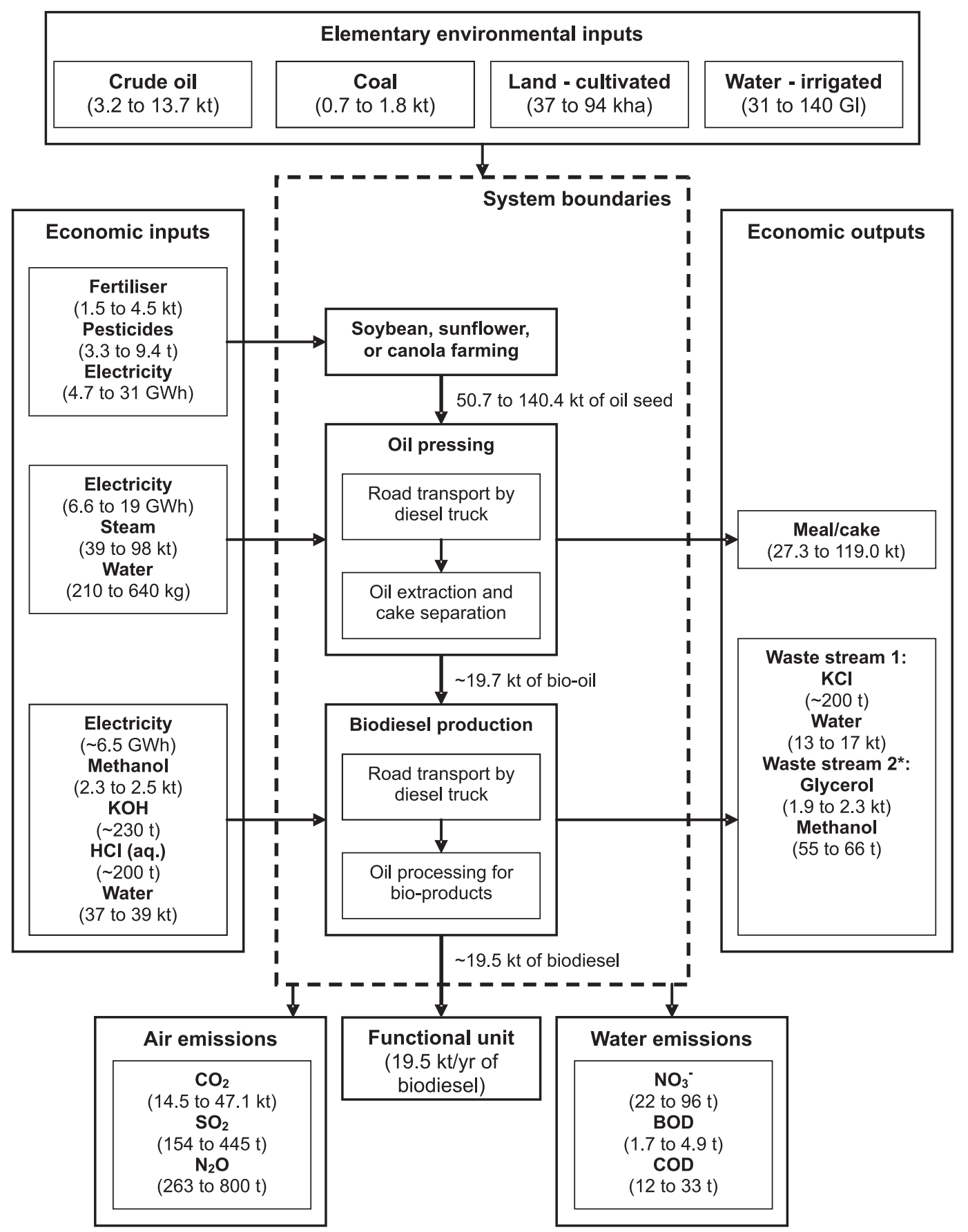

* Glycerol, and also potentially methanol, can be recovered and sold; therefore, stream 2 may not constitute a waste, but a by-product

Figure 3: General biodiesel production system

(Details of the variations in the values are provided in Table 2)

from the biodiesel production unit process, were excluded from the system boundaries.

The exclusion of these outputs is important from an allocation perspective. A recent publication (Guinée and Heijungs, 2007) has shown that different allocation methods could (potentially) generate large differences in allocation factors and consequently also at the level of environmental impacts of fuel chains. Much of the literature discusses the choice of parameter to base allocation on; for example, mass, economic, or energy (calorific) value of the (by)-products.

For this life cycle inventory, allocation was not considered, namely all the economic and elementary environmental flows are allocated solely to the biodiesel product. Assumptions will subsequently 
have to be made with future studies that utilise this inventory, especially since the meal/cake, at present, is the most important economic product from the feedstock production for some crops, particularly for soybean.

Similar to previous biodiesel studies (Sheehan et al., 1998), the environmental flows associated with producing capital equipment and facilities in the life cycle were not considered. For petroleum diesel life cycles, these flows have been shown to be negligible (Sheehan et al., 1998). In the case of biodiesel, the biomass resources are less energy dense and concentrated and the energy embodied in the construction of the equipment and facilities in the life cycle may be more significant. However, to be consistent with other fuel chains, these life cycle flows were excluded from the inventory.

\subsection{Description of unit processes' data}

Table 1 summarises the key parameters for the farming unit process. The yields of the soybean, sunflower, and canola feedstock crops were estimates for the 2005/6 growing season, which were obtained from Grain South Africa, a non-profit organisation, and from a study of the University of Pretoria. Fertilizer application for each crop was provided by the Fertilizer Society of South Africa, a non-profit company that represents the interests of the fertilizer and agricultural lime industries in South Africa. The different fatty acid methyl esters (FAME) densities were obtained from literature (Pischinger et al., 1982; Schwab et al., 1987).

For uncertainty analyses, minimum and maximum percentages of oil and meal/cake in the seed were derived from international data (Sheehan et al., 1998). The maximum amount of water needed, as extracted from a catchment area, was assumed to be the requirement of the crop for optimal growth. The minimum water needed was assumed to be the irrigation requirements only, as the rainfall of the regions, which was obtained from the South African Department of Environmental Affairs and Tourism, was subtracted from the requirement of the crop. Minimum and maximum calculations of all the other flows to and from the farming unit process were based on the differences in oil in the seed.

The transportation, from the farming unit process to the oil presses, was calculated by assuming that trucks greater than 32 tonnes would be utilised. According to the Road Transport Annex in the EMEP/CORINAIR Emission Inventory Guidebook (EEA, 2006), for a fully loaded articulated truck travelling between 40 and $60 \mathrm{~km} / \mathrm{h}$ at $0 \%$ gradient and for European emission standards in the 1980s, approximately 0.55 litres of diesel would be needed per kilometre. For the same truck carrying no load, 0.3 litres $/ \mathrm{km}$ would be needed. An average of 0.43 litres $/ \mathrm{km}$ was assumed for this study. It was further assumed that oil presses would be located in

Table 1: Key parameters for the farming unit process (2005/6 growing season)

\begin{tabular}{|c|c|c|c|c|}
\hline \multirow[t]{2}{*}{ Parameter } & \multirow[t]{2}{*}{ Unit } & \multicolumn{3}{|c|}{ Crop } \\
\hline & & Soybean & Sunflower & Canola \\
\hline Area grown & ‘000 ha & 120 & 640 & 20 \\
\hline Average yield - South Africa ${ }^{a, b}$ & tonnes/ha & 1.70 & 1.31 & 1.42 \\
\hline$\overline{\text { Fertilizer consumption }-\mathrm{N}^{\mathrm{c}}}$ & $\mathrm{kg} / \mathrm{ha}$ & 7 & 15 & 40 \\
\hline Fertilizer consumption $-\mathrm{Pc}$ & $\mathrm{kg} / \mathrm{ha}$ & 25 & 21 & 7 \\
\hline Fertilizer consumption $-\mathrm{K}^{\mathrm{c}}$ & $\mathrm{kg} / \mathrm{ha}$ & 8 & 2 & 36 \\
\hline Fertilizer consumption - total ${ }^{\mathrm{c}}$ & $\mathrm{kg} /$ tonne crop & 25.0 & 24.1 & 58.5 \\
\hline FAME density & $\mathrm{kg} / \mathrm{kl}$ & 880 & 884 & 920 \\
\hline Minimum meal percentage & $\%$ & 78.5 & 56.0 & 59.0 \\
\hline Maximum meal percentage & $\%$ & 84.5 & 75.0 & 72.0 \\
\hline Minimum oil percentage & $\%$ & 15.5 & 25.0 & 28.0 \\
\hline Maximum oil percentage & $\%$ & 21.5 & 44.0 & 41.0 \\
\hline Minimum water required - irrigation $^{\mathrm{d}}$ & $\mathrm{Ml} /$ tonne crop & 0.56 & 0.36 & 0.65 \\
\hline Maximum water required - irrigation ${ }^{\mathrm{d}}$ & $\mathrm{Ml} /$ tonne crop & 1.40 & 1.10 & 1.20 \\
\hline
\end{tabular}

a Food and Agricultural Policy Research Institute (FAPRI), University of Missouri College of Agriculture Food and Natural Resources, University of Pretoria, (2004): Final report for the University of Missouri South African education program. FAPRI-UMC Report \#07-04, www.fapri.missouri.edu/outreach/publications/2004/FAPRI_UMC_ Report_07_04.pdf

b Grain South Africa, www.grainsa.co.za

c Fertilizer Society of South Africa, www.fssa.org.za

d South African Department of Environmental Affairs and Tourism, www.environment.gov.za/enviroinfo/prov/rain.htm 
the provinces, within $500 \mathrm{~km}$ of the farming activities, but at an average distance of $100 \mathrm{~km}$; this is in line with findings elsewhere (Sheehan et al., 1998). Similar distances and modes were assumed for the transportation from the oil presses to the production plant. The petroleum resource requirements are directly reported as elementary flows of crude oil and coal.

The energy usages in the oil pressing and biodiesel production unit processes were mostly derived from international data (Sheehan et al., 1998), but updated with site-specific and design information in the South African context. Specifically, electricity and steam usages reflect the situation in South Africa. Similarly, the other chem- ical material inputs in the biodiesel production unit process were obtained from detailed South African designs and models.

The emissions to air and water were primarily obtained from international databases (Sheehan et al., 1998).

\subsection{Description of data categories}

The data was categorised into economic flows and elementary environmental flows. The economic flows are reported as such in the inventory and are not converted to elementary flows. Thereby local and region specific information may be used to expand the elementary flows; for example, the electricity (Koch and Harnisch, 2002) and water (Lan-

Table 2: Comparative summary table for the different feedstock (for a production year)

\begin{tabular}{|c|c|c|c|c|}
\hline \multirow[t]{2}{*}{ Flow } & Soybean & Sunflower & \multicolumn{2}{|c|}{ Canola } \\
\hline & $\begin{array}{cc}\text { Min } & \text { Max } \\
\text { / } 19.5 \mathrm{kt} & \text { biodiesel }\end{array}$ & $\begin{array}{cc}\text { Min } & \text { Max } \\
\text { / } 19.5 \mathrm{kt} & \text { biodiesel }\end{array}$ & $\begin{array}{c}\text { Min } \\
/ 19.5 \mathrm{kt}\end{array}$ & $\begin{array}{c}\text { Max } \\
\text { biodiesel }\end{array}$ \\
\hline
\end{tabular}

\begin{tabular}{|c|c|c|c|c|c|c|}
\hline \multicolumn{7}{|l|}{ Economic inputs } \\
\hline Electricity [GWh] & 32 & 39 & 26 & 44 & 18 & 29 \\
\hline Steam $[\mathrm{kt}]$ & 59 & 98 & 39 & 59 & 39 & 59 \\
\hline Methanol [kt] & 23 & 25 & 23 & 25 & 23 & 25 \\
\hline$\overline{\mathrm{KOH}}[\mathrm{t}]$ & 230 & 230 & 230 & 230 & 230 & 230 \\
\hline$\overline{\mathrm{HCl} \text { (aq.) }[\mathrm{t}]}$ & 200 & 200 & 200 & 200 & 200 & 200 \\
\hline Fertliser [kt] & 1.6 & 3.7 & 1.5 & 2.7 & 2.9 & 4.5 \\
\hline $\mathrm{N}[\mathrm{kt}]$ & 0.3 & 0.7 & 0.6 & 1.1 & 1.4 & 2.1 \\
\hline $\bar{P}[\mathrm{kt}]$ & 1.0 & 2.3 & 0.8 & 1.5 & 0.3 & 0.4 \\
\hline $\mathrm{K}[\mathrm{kt}]$ & 0.3 & 0.8 & 0.1 & 0.2 & 1.3 & 1.9 \\
\hline Pesticides [t] & 6.8 & 9.4 & 3.3 & 5.9 & 3.5 & 5.1 \\
\hline Water -processing [kt] & 37 & 39 & 37 & 39 & 37 & 39 \\
\hline \multicolumn{7}{|l|}{ Economic outputs } \\
\hline Bio-diesel [kt] & \multicolumn{6}{|c|}{19.5} \\
\hline Meal/cake [kt] & 80.0 & 119.0 & 27.3 & 66.3 & 29.3 & 54.6 \\
\hline \multicolumn{7}{|l|}{ Waste stream 1} \\
\hline $\mathrm{KCl}$ (aq.) [kt] & 0.2 & 0.2 & 0.2 & 0.2 & 0.2 & 0.2 \\
\hline Water [kt] & 13 & 17 & 13 & 17 & 13 & 17 \\
\hline \multicolumn{7}{|l|}{ Waste stream 2} \\
\hline Glycerol [kt] & 1.9 & 2.3 & 1.9 & 2.3 & 1.9 & 2.3 \\
\hline Methanol $[\mathrm{kt}]$ & 0.06 & 0.07 & 0.06 & 0.07 & 0.06 & 0.07 \\
\hline \multicolumn{7}{|c|}{ Elementary inputs and outputs } \\
\hline Land - cultivated [kha] & 41 & 94 & 37 & 70 & 37 & 53 \\
\hline Water - irrigated [Gl] & 78 & 140 & 31 & 55 & 49 & 64 \\
\hline Crude oil [kt] & 9.2 & 13.7 & 4.1 & 8.9 & 3.2 & 6.4 \\
\hline Coal $[\mathrm{kt}]$ & 1.4 & 1.8 & 0.7 & 1.2 & 0.8 & 1.1 \\
\hline $\mathrm{CO} 2[\mathrm{kt}]$ & 38.0 & 47.1 & 14.5 & 30.1 & 16.9 & 29.1 \\
\hline $\mathrm{SO}_{2}[\mathrm{t}]$ & 263 & 445 & 154 & 238 & 158 & 210 \\
\hline $\mathrm{N}_{2} \mathrm{O}[\mathrm{t}]$ & 710 & 800 & 263 & 530 & 265 & 476 \\
\hline $\mathrm{NO}_{3}{ }^{-}$(water) [t] & 22 & 37 & 41 & 45 & 96 & 96 \\
\hline BOD (water) [t] & 3.5 & 4.9 & 1.7 & 2.9 & 1.7 & 2.5 \\
\hline COD (water) [t] & 25 & 33 & 12 & 21 & 12 & 18 \\
\hline
\end{tabular}


du and Brent, 2006) supply scenarios.

For the farming unit process, all the data of the economic inputs reflect South African values, except for the pesticides requirements. The elementary flows are primarily based on international data (Sheehan et al., 1998) except for the land and water usage, which are South African specific. For the oil pressing and biodiesel unit processes, the economic flows reflect South African practices and design models, but the elementary flows were obtained from published data (Sheehan et al., 1998).

In terms of the elementary environmental flows, the chosen inputs and outputs were based on the availability of data, the quality of published background information, and the main environmental categories that have been considered by various life cycle assessment publications (Weiss et al., 2007):

- Non-renewable resources usage, i.e. crude oil and coal, which are aggregate for the three main unit processes.

- Land usage, as existing agricultural land for the farming unit process.

- Water usage, of a quality deemed suitable for agricultural irrigation in terms of the South African water quality guidelines (DWAF, 1996).

- Global warming potential (GWP).

- Acidification potential (AP).

- Eutrophication potential (EP).

- Other damages to water resources.

\section{Life cycle inventory analysis and discussion}

The detailed inventory dataset is provided elsewhere (BIOISSAM, 2010: www.biossam.org/wpcontent/uploads/2010/08/Life-cycle-inventory-datafor-biodiesel-scenarios.pdf) and summarised in Table 2. For the farming unit processes, data values are provided for the reference flow of the unit process, namely 1 tonne of produced oil seed, and for the functional unit of the complete life cycle, namely $19.5 \mathrm{kt} / \mathrm{yr}$ of biodiesel product. Per reference flow, the variations in the data reflect differences between the Provinces, except for canola where country average values were used. Per functional unit, the variations in the data reflect uncertainties throughout the life cycle.

For the oil pressing unit processes, which include the transportation from the respective farming unit processes, the data values are again provided for the reference flow of the unit process, namely 1 tonne of processed oil seed, and for the functional unit of the complete life cycle. Variations in the data per reference flow are due to the potential differences in the oil and meal/cake content of the oil seed. Per functional unit, the uncertainties across the value chain are reflected in the variations of the data.

Data values are provided for the biodiesel pro- duction unit process, which includes the transportation from the oil pressing unit processes, per a reference flow of 1 tonne of biodiesel produced, and per the functional unit of $19.5 \mathrm{kt} / \mathrm{yr}$. Uncertainties are due to the location of the facilities, which has a minor influence, and the interactions between unit processes in the value chain.

\subsection{Sensitivity and uncertainty analyses}

The farming unit process showed significant sensitivity to the type of crop and region of production. For example, the inputs and outputs of sunflower, except for water usage, do not differ much between the Provinces, but due to yield differences in soybean production, the values may differ by a factor of two. Such variability has also been reported elsewhere (Landis et al., 2007).

The availability of data, and how it is reported, also plays a significant role. For example, energy usage on the farm is often reported per hectare and emissions, in international databases, per tonne produced. The consequence is that emissions may not seem sensitive to feedstock production yields, although, of course, they should. The water usage ranges by a factor of two for soybean and canola, and by a factor of nearly three for sunflower, which highlights the importance of rainfall in a region in terms of the requirement to extract water from a catchment.

The oil and meal/cake content of the seed produce influences the elementary flows associated with the transportation requirements to the oil pressing unit process, although the South African field trip data suggests that it is not a very important factor in terms of energy usage at the oil pressing facilities. However, the oil and meal/cake content proves to be the most important parameter that influences the unit processes in the initial life cycle phases. Almost all the inputs and outputs of the farming unit processes, for all the crops, range in the order of a factor of two due to variations in this parameter.

Section 3.2 indicates that, at present, the meal/cake co-product has an economic value, often more than the fuel product. However, should there not be an offset market, the production system would face a significant waste stream; between 27 and 120 kilo tonnes for 19.5 tonnes of biodiesel. This, together with the other waste streams, most notably $\mathrm{KCl}$ (around 200 tonnes) and glycerol (2 kilo tonnes), would necessitate a separate waste management systems in the economy (see Figure $3)$.

The uncertainties associated with the logistic system in the value chain have major implications. For example, should the distances from the farming activities to the oil pressing unit process, and to the biodiesel production unit process, increase by a factor of two, then the energy balance may be negative 
(with soybean as feedstock). Indications are that average distances should not exceed $300 \mathrm{~km}$ in the product value chain.

Very little uncertainties were detected in the biodiesel production unit process. However, the energy efficiency of the overall system needs due consideration. On average, the 19.5 kilo tonnes biodiesel product has an energy-content in the order of $800 \mathrm{TJ}$; the energy demand of the system is in the order of 400 to $1100 \mathrm{TJ}$. This means that the nearly half of all the production may be an energy sink, which is clearly unsustainable.

\subsection{Interpretation and limitation of the inventory dataset}

From the sensitivity and uncertainty analyses, it would seem that the most important system parameters that need attention in terms of accuracy to establish an environmental profile are:

- The crop yields, and therefore land usage;

- The water usage;

- The oil and meal/cake content of the seed produce; and

- The logistics system.

There are, however, a number of limitations with the inventory. For example:

- The geographical representation of available data remains a problem for most of the elementary flows and for the initial unit processes of value chains, especially in the South African context (Brent et al., 2002).

- Farming practices are not captured in the flows of such a simplified inventory. For example, crop rotation is vital to preserve soil quality in most regions of South Africa, and the chemicals used may differ significantly between regions (Brent et al., 2009).

- The inventory focuses on the scenarios of the biofuels industrial strategy of South Africa in that existing agricultural land, for cultivation, is occupied for the crop production (Brent et al., 2009). The potential requirement to transform land is not captured, which, in turn, may have a significant influence on ecosystems' structure and functioning (Achten et al., 2007).

- The temporal scale of the inventory dataset is problematic in that values for certain harvest years are utilised, but there are great variations in wet and dry periods in South Africa that would increase the uncertainty of the inventory (Brent et al., 2009).

\section{Implications for environmental impact profiles of South African biofuel value chains}

The limitations of the inventory dataset (BIOSSAM, 2010) highlight the challenge with deriving comprehensive impact assessment profiles for biodiesel production. Much emphasis has been placed on energy balances and air emissions of such life cycle systems, but the following aspects are yet to be addressed:

- Although frameworks of land use are in development (i Canals et al., 2007), the conventional definition of land usage flow, in life cycled assessment terms, is deemed inadequate to reflect changes in the quantity and quality of land resources in these studies. However, biodiversity indexes have been proposed to evaluate land usage changes (Scholes and Biggs, 2005) that could be used to define appropriate land usage flows.

- The definitions of the water usage and effluent flows in the inventory datasets are deemed inadequate to reflect changes in the quantity and quality of water resources (Brent, 2004). Similar to the land resources, the diversity at microbial level has been proposed as an index that can be utilised to define water usage and release flows (Suridge and Brent, 2008).

- There is currently no approach to handle the solid waste streams of biofuel value chains.

With respect to the air emissions, the life cycle inventory compares reasonably to other studies (Rollefson et al., 2004; Beer et al., 2007). For example, $\mathrm{CO}_{2}$ emissions are in the same order of magnitude. However, the emissions of $\mathrm{N}_{2} \mathrm{O}$ are very high with a contribution to global warming potential (GWP) in the order of three-hundred times that of $\mathrm{CO}_{2}$; the consequence is that the variability in overall GWP is between 4.5 and 14.5 tonnes of $\mathrm{CO}_{2}$ equivalent per tonne of biodiesel produced (see Table 3). This highlights the necessity to also refine the accuracy of the conventional flows in the inventory dataset for the South African context.

\section{Conclusions}

The introduction of the new biofuels industrial strategy in South Africa has emphasised the need to understand the potential environmental implications of biofuel scenarios in the South African context. As yet there is no structured approach to establish environmental profiles of the envisaged value chains in the scenarios of the strategy.

This paper consequently aims to provide a foundation for the further development of comprehensive life cycle inventories of biofuels production. The paper focuses on commercial-scale seed extraction biodiesel production, although it is envisaged that the inventory dataset will be developed further for small-scale and other distributed and co-production routes. Three crops are currently included in the strategy for biodiesel production, namely soybean, sunflower, and canola. Comparative LCI analyses were conducted for these crops for a 19.5 $\mathrm{kt} / \mathrm{yr}$ production facility, which is considered to be an optimal capacity in the South African context. 
Table 3 lists the overall inventory per tonne of biodiesel produced.

\subsection{Emphasis for policy-makers}

The inventory analysis shows that the inputs and outputs of the farming unit process are sensitive to the type of crop and region of produce. Water usage is a highly variable parameter, which emphasises the importance of rainfall and irrigation to the overall burden of the biodiesel system on water resources. Crop yields may differ by a factor of two, which is a significant difference in terms of land and non-renewable energy resources requirements. The oil and meal/cake content of the seed proves to be the most important parameter that influences the initial unit processes of the value chains. Almost all the inputs and outputs of the farming unit processes, for the all the crops, range in the order of a factor of two due to this parameter. The uncertainties associated with the logistic system in the value chain also have major implications. If no market offset is available for the meal/cake co-products then due consideration is necessary of the necessary waste treatment uncertainties, which is also true for the other waste streams, most notably $\mathrm{KCl}$ and glycerol. Very little uncertainties were detected in the biodiesel production unit process, although the energy efficiency of the overall production system remains questionable.

A number of limitations are identified with the

Table 3: Overall inventory per tonne of biodiesel produced

\begin{tabular}{|c|c|c|c|c|c|c|}
\hline \multirow[t]{2}{*}{ Flow } & \multicolumn{2}{|c|}{ Soybean } & \multicolumn{2}{|c|}{ Sunflower } & \multicolumn{2}{|c|}{ Canola } \\
\hline & $\begin{array}{l}\text { Min } \\
\text { /tonne }\end{array}$ & $\begin{array}{c}\text { Max } \\
\text { biodiesel }\end{array}$ & $\begin{array}{l}\text { Min } \\
\text { /tonne }\end{array}$ & $\begin{array}{c}\text { Max } \\
\text { biodiesel }\end{array}$ & $\begin{array}{l}\text { Min } \\
\text { /tonne }\end{array}$ & $\begin{array}{c}\text { Max } \\
\text { biodiesel }\end{array}$ \\
\hline \multicolumn{7}{|l|}{ Economic inputs } \\
\hline Electricity [kWh] & 1640 & 2000 & 1330 & 2260 & 923 & 1490 \\
\hline Steam [t] & 3.3 & 5.0 & 2.0 & 3.0 & 2.0 & 3.0 \\
\hline Methanol [kg] & 118 & 128 & 118 & 128 & 118 & 128 \\
\hline$\overline{\mathrm{KOH}}[\mathrm{kg}]$ & 11.8 & 11.8 & 11.8 & 11.8 & 11.8 & 11.8 \\
\hline $\mathrm{HCl}$ (aq.) [kg] & 10.3 & 10.3 & 10.3 & 10.3 & 10.3 & 10.3 \\
\hline Fertliser $[\mathrm{kg}]$ & 82.1 & 190 & 76.9 & 138 & 149 & 231 \\
\hline $\mathrm{N}[\mathrm{kg}]$ & 14.9 & 33.8 & 30.8 & 56.4 & 71.8 & 108 \\
\hline $\mathrm{P}[\mathrm{kg}]$ & 51.3 & 118 & 43.1 & 76.9 & 12.8 & 19.0 \\
\hline $\mathrm{K}[\mathrm{t}]$ & 16.9 & 39 & 4.0 & 8.2 & 66.7 & 97.4 \\
\hline Pesticides [g] & 349 & 482 & 169 & 303 & 179 & 262 \\
\hline Water-processing [t] & 1.9 & 2.0 & 1.9 & 2.0 & 1.9 & 2.0 \\
\hline \multicolumn{7}{|l|}{ Economic outputs } \\
\hline Biodiesel [t] & \multicolumn{6}{|c|}{1} \\
\hline Meal/cake [t] & 4.1 & 6.1 & 1.4 & 3.4 & 1.5 & 2.8 \\
\hline \multicolumn{7}{|l|}{ Waste stream 1} \\
\hline 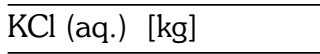 & 10.3 & 10.3 & 10.3 & 10.3 & 10.3 & 10.3 \\
\hline Water $[\mathrm{t}]$ & 0.7 & 0.9 & 0.7 & 0.9 & 0.7 & 0.9 \\
\hline \multicolumn{7}{|l|}{ Waste stream 2} \\
\hline Glycerol [kg] & 97.4 & 118 & 97.4 & 118 & 97.4 & 118 \\
\hline Methanol $[\mathrm{kg}]$ & 2.8 & 3.4 & 2.8 & 3.4 & 2.8 & 3.4 \\
\hline \multicolumn{7}{|c|}{ Elementary inputs and outputs } \\
\hline Land - cultivated [ha] & 2.1 & 4.8 & 1.9 & 3.6 & 1.9 & 2.7 \\
\hline Water - irrigated [Ml] & 4.0 & 7.2 & 1.6 & 2.8 & 2.5 & 3.3 \\
\hline Crude oil [t] & 0.5 & 0.7 & 0.2 & 0.5 & 0.2 & 0.3 \\
\hline Coal [kg] & 71.8 & 92.3 & 35.9 & 61.5 & 41.0 & 56.4 \\
\hline $\mathrm{CO}_{2}[\mathrm{t}]$ & 2.0 & 2.4 & 0.7 & 1.5 & 0.9 & 1.5 \\
\hline $\mathrm{SO}_{2}[\mathrm{~kg}]$ & 13.5 & 22.8 & 7.9 & 12.2 & 8.1 & 10.8 \\
\hline $\mathrm{N}_{2} \mathrm{O}[\mathrm{kg}]$ & 36.4 & 41.0 & 13.5 & 27.2 & 13.6 & 24.4 \\
\hline $\mathrm{NO}_{3}^{-}$(water) [kg] & 1.1 & 1.9 & 2.1 & 2.3 & 4.9 & 4.9 \\
\hline BOD (water) [kg] & 0.2 & 0.3 & 0.1 & 0.2 & 0.1 & 0.1 \\
\hline COD (water) [kg] & 1.3 & 1.7 & 0.6 & 1.1 & 0.6 & 0.9 \\
\hline
\end{tabular}


inventory dataset. For example, published emissions data are often reported per reference flow and do not reflect geographical differences. Certain elementary environmental flows are not captured such as the impacts on soil quality due to farming practices. Also, the elementary flow for land usage is regarded to be occupied agricultural land for cultivation as per the biofuels industrial strategy. Cognisance must be taken where a biofuel value chain requires the transformation of ecosystems. Finally, the temporal scale of the inventory dataset is problematic. The annual variations in agricultural production are large in South Africa, which, together with expected behavioural changes due to the introduction of the biofuels industrial strategy, makes comprehensive uncertainty analyses difficult at present.

The paper also considers the implications to assess the environmental impact profiles for further decision-making purposes. To date, much emphasis has been placed on energy balances and air emissions of such bioenergy systems, but certain aspects are raised that must be addressed; specifically pertaining to land use, water use, and solid waste streams. The global warming potential category is also used to highlight the necessity to improve the accuracy of the conventional flows of the inventory dataset in the South African context. For the biodiesel value chain $\mathrm{N}_{2} \mathrm{O}$ emissions, especially, need to be refined to reduce the uncertainty. Although the global warming potential of agricultural activities are estimated on a global aggregate level (IPCC, 2007), major uncertainties are still reported in the current national emissions inventory (Taviv et al., 2007).

\section{References}

Achten, W.M.J., Mathijs, E., Verchot, L., Singh, V.P., Aerts, R., and Muys, B., (2007). Jatropha biodiesel fuelling sustainability? Biofuels, Bioproducts and Biorefining, 1: 283-291.

Beer, T., Grant, T., and Campbell, P.K., (2007). The greenhouse and air quality emissions of biodiesel blends in Australia. CSIRO Report Number KS54C/1/F2.27, www.csiro.au/ resources /greenhouse-air-quality-emissions-biodieselblends.html, accessed 24 August 2010.

Berndes, G., (2002). Bioenergy and water: The implications of large-scale bioenergy production for water use and supply. Global Environmental Change, 12: 253-271.

BIOSSAM (Bioenergy Systems Sustainability Assessment and Management portal) (2010). Life cycle inventories to analyse biodiesel value chains. http://www.biossam.org/case-studiesand-pilot-programmes/biodiesel/life-cycle- inventories/, accessed 24 August 2010.

Brent, A.C., Wise, R., and Fortuin, H., (2009). The viability of the South African biofuels industrial strategy. International Journal of Environment and Pollution, 39(1/2): 74-91.

Brent, A.C., (2004). A life cycle impact assessment procedure with resource groups as areas of protection. International Journal of Life Cycle Assessment, 9(3): 172-179.

Brent, A.C., Rohwer, M.B., Friedrich, E., and von Blottnitz, H., (2002). Status of life cycle assessment and engineering research in South Africa. International Journal of Life Cycle Assessment, 7(3): 167-172.

Department of Minerals and Energy (DME) (2007). Biofuels industrial strategy of the Republic of South Africa. Directorate of Clean Energy and Energy Planning, www.dme.gov.za/energy/documents.stm, accessed 24 August 2010.

Department of Minerals and Energy (DME) (2003). White Paper on Renewable Energy. www.dme.gov.za/energy/documents.stm, accessed 24 August 2010.

Department of Water Affairs and Forestry (DWAF) (1996). South African water quality guidelines. www.dwaf.gov.za/Dir_WQM/docsFrame.htm, accessed 24 August $20 \overline{10}$.

Derpsch, R., (2005). The extent of conservation agriculture adoption worldwide: Implications and impact. Proceedings of the Third World Congress on Conservation Agriculture: Linking Production, Livelihoods and Conservation, Nairobi, Kenya.

European Environment Agency (EEA) (2006). Road Transport Annex, Group 7: Road Transport. EMEP/CORINAIR Emission Inventory Guidebook, Brussels.

Guinée, J.B., and Heijungs, R., (2007). Calculating the influence of alternative allocation scenarios in fossil fuel chains. International Journal of Life Cycle Assessment, 12(3): 173-180.

Harding, K.G., Dennis, J.S., von Blottnitz, H., and Harrison, S.T.L., (2008). A life-cycle comparison between inorganic and biological catalysis for the production of biodiesel. Journal of Cleaner Production, 16(13): 1368-1378.

Canals, L.M., Müller-Wenk, R., Bauer, C., Depestele, J., Dubreuil, A., Knuchel, R.F., Gaillard, G., Michelsen, O., and Rydgren, B., (2007). Key elements in a framework for land use impact assessment within LCA. International Journal of Life Cycle Assessment, 12(1): 5-15.

IPCC (2007). Changes in atmospheric constituents and in radiative forcing. Contribution of Working Group I to the Fourth Assessment Report of the Intergovernmental Panel on Climate Change, www.ipcc.ch/pdf/assessmentreport/ar4/wg1/ar4-wg1-chapter2.pdf, accessed 24 August 2010.

Jungmeier, G., Werner, F., Jarnehammar, A., Hohenthal, C., and Richter, K., (2002). Allocation in LCA of wood-based products: Experiences of Cost Action E9 - Part I. Method- 
ology. International Journal of Life Cycle Assessment, 7(5): 290-294.

Kim, S., and Dale, B.E., (2006). Ethanol fuels: E10 or E85 - Life cycle perspectives. International Journal of Life Cycle Assessment, 11(2): 117121.

Kim, S., and Dale, B.E., (2005). Life cycle assessment of various cropping systems utilized for producing biofuels: Bioethanol and biodiesel. Biomass and Bioenergy, 29(6): 426-439.

Koch, M., and Harnisch, J., (2002). $\mathrm{CO}_{2}$ emissions related to the electricity consumption in the European primary aluminium production: A comparison of electricity supply approaches. International Journal of Life Cycle Assessment, 7(5): 283-289.

Landis, A.E., Miller, S.A., and Theis, T.L., (2007). Life cycle of the corn-soybean agroecosystem for biobased production. Environmental Science and Technology, 41(4): 1457-1464.

Landu, L., and Brent, A.C., (2006). Environmental life cycle assessment of water supply in South Africa: The Rosslyn industrial area as a case study, Water SA, 32(2): 249-256.

National Biofuels Task Team (NBTT) (2006). National biofuels study: An investigation into the feasibility of establishing a biofuels industry in the Republic of South Africa. www.dme.gov.za/ energy/documents.stm, accessed 24 August 2010.

Nolte, M., (2007). Commercial biodiesel production in South Africa: A preliminary economic feasibility study. Masters Degree Thesis, University of Stellenbosch, http://scholar.sun.ac.za/handle/ 10019 .1/1797, accessed 24 August 2010.

Pischinger, G.M., Falcon, A.M., Siekmann, R.W., and Fernandes, F.R., (1982). Methyl esters of plant oils as diesel fuels, either straight or in blends. Vegetable Oil Fuels, American Society of Agricultural Engineers Publication 4-82, St. Joseph, MI, USA.

Pro, B.H., Hammerschlag, R., and Mazza, P., (2005). Energy and land use impacts of sustainable transportation scenarios. Journal of Cleaner Production, 13: 1309-1319.

Rollefson, J., Fu, G., and Chan, A., (2004). Assessment of the environmental performance and sustainability of biodiesel in Canada. National Research Council, Canada, www. greenfuels.org/biodiesel/res/2004_11_NRCBiodi eselProjectReportNov04.pdf, accessed 24 August 2010.

Scholes, R.J., and Biggs, R., (2005). A biodiversity intactness index. Nature, 434: 45-49.

Schwab, A.W., Bagby, M.O., and Freedman, B., (1987). Preparation and properties of diesel fuels from vegetable oils. Fuel, 66: 1372-1378.

Sheehan, J., Camobreco, V., Duffield, J., Graboski, M., and Shapouri, H., (1998). Life cycle inventory of biodiesel and petroleum diesel for use in an urban bus. Final report, NREL/SR-58024089 report, www.nrel.gov/docs/legosti/fy98/ 24089.pdf, accessed 24 August 2010.
Spirinckx, C., and Ceuterick, D., (1996). Biodiesel and fossil diesel fuel: Comparative life cycle assessment. International Journal of Life Cycle Assessment, 1(3): 127-132.

Suridge, A.K.J., and Brent, A.C., (2008). Development of a water state index to assess the severity of impacts on and changes in natural water resources. Water Science and Technology, 58(8): 1595-1600.

Tait, B., (2005). Requirements and viability for biofuels in South Africa. Fertilizer Society of South Africa Journal, 25: 27-28.

Taviv R., van der Merwe M., Scholes R.J., and Collet G., (2007). Non-energy emissions: Agriculture, forestry and waste. LTMS Input Report 2, Department of Environmental Affairs and Tourism, www.environment.gov.za/Hotlssues/2009/LTMS2/AgricultureForest ryWaste.pdf, accessed 24 August 2010.

Von Blottnitz, H., and Curran, M.A., (2007). A review of assessments conducted on bioethanol as a transportation fuel from a net energy, greenhouse gas, and environmental life cycle perspective. Journal of Cleaner Production, 15(7): 607-619.

Weiss, M., Patel, M., Heilmeier, H., and Bringezu, S., (2007). Applying distance-to-target weighting methodology to evaluate the environmental performance of bio-based energy, fuels and materials. Resources, Conservation and Recycling, 50: 260-281.

Received 2 April 2009; revised 11 October 2010 